\title{
Pola Perubahan Kemampuan Argumentasi Ilmiah melalui Model Pembelajaran Kontekstual Multirepresentasi
}

\author{
Lenny Agustina Suwastika Sari ${ }^{1}$, Markus Diantoro ${ }^{1}$, Muhardjito ${ }^{1}$ \\ ${ }^{1}$ Pendidikan Fisika-Universitas Negeri Malang
}

\begin{tabular}{l}
\hline \hline INFO ARTIKEL \\
\hline Riwayat Artikel: \\
Diterima: 28-05-2019 \\
Disetujui: $12-09-2019$ \\
\hline
\end{tabular}

\section{Kata kunci:}

the ability of scientific argumentation; contextual learning model, multi-representation;

kemampuan argumentasi ilmiah model pembelajaran kontekstual; multirepresentasi

\author{
Alamat Korespondensi: \\ Lenny Agustina Suwastika Sari \\ Pendidikan Fisika \\ Universitas Negeri Malang \\ Jalan Semarang 5 Malang \\ E-mail: lennyagustina375@gmail.com
}

\begin{abstract}
ABSTRAK
Abstract: This study aims to determine the ability of scientific argumentation of students. The study was conducted on 64 of students X-MIPA class on force and motion. The results of the observation showed that the argument ability of the concept force and motion in students was still very low. The low ability of participants' scientific arguments could also influenced by inappropriate learning models. The learning model applied is a multi-representation based contextual learning model was implemented. The results showed that there was an improve in the ability of scientific argumentation after applying a multi-presentation based contextual learning model. Analysis obtained was $0 \%$ at level $17.18 \%$ at level $43.75 \%$ at level $37.13 \%$ at level 4 and $10.94 \%$ at level 5 .

Abstrak: Penelitian ini bertujuan untuk mengetahui kemampuan argumentasi ilmiah siswa. Penelitian dilakukan pada 64 siswa kelas X-MIPA materi gaya dan gerak. Hasil pengamatan menunjukkan kemampuan argumentasi konsep gaya dan gerak pada siswa masih sangat rendah. Kemampaun argumentasi ilmiah yang rendah juga dipengaruhi oleh model pembelajaran yang kurang tepat. Model pembelajaran yang diterapkan adalah model pembelajaran kontekstual berbasis multirepresentasi. Hasil penelitian menunjukkan ada peningkatan kemampuan argumentasi ilmiah setelah menerapkan model pembelajaran kontekstual berbasis multirepresentasi. Analisis yang diperoleh $0 \%$ pada level 1, $17.18 \%$ pada level 2, 43.75\% pada level 3,37.13\% pada level 4 dan $10.94 \%$ pada level 5.
\end{abstract}

Sebagian besar siswa memiliki masalah dalam memahami konsep gaya (Halim, Yong, \& Meerah, 2014) karena gaya dan gerak terdiri dari konsep abstrak yang kadang sulit dipelajari oleh siswa (Alias \& Ibrahim, 2016). Gaya adalah konsep inti untuk dapat mempelajari Hukum Newton (Halim et al., 2014). Jika siswa tidak memahami dan menguasai konsep Hukum Newton tentang gerak maka materi selanjutnya sulit dipahami siswa karena konsep Hukum Newton tentang gerak adalah konsep dasar dalam materi fisika sehingga membutuhkan perencanaan, prosedural dan kegiatan yang cocok agar konsep gaya dan gerak dapat dipahami dengan baik oleh siswa. Kesulitan siswa dalam memahami suatu konsep juga dikarenakan argumentasi ilmiah siswa yang masih rendah dalam mengevaluasi dan mengonstruk pengetahuan. Argumentasi ilmiah adalah salah satu kemampuan yang penting dimiliki oleh siswa, karena siswa yang memiliki kemampuan argumentasi ilmiah yang baik dapat membangun penjelasan untuk menghasilkan pengetahuan baru. Pengetahuan baru ini berupa teori baru, pengalaman baru, cara baru dalam mengumpulkan data atau cara baru dalam menyelesaikan suatu permasalahan (Eskin \& Ogan-Bekiroglu, 2013; National Research Council, 2008; Osborne, 2010; Wang \& Buck, 2016).

Dari kesulitan-kesulitan yang dimiliki oleh siswa, hendaknya dalam pembelajaran mampu menggiring siswa menggabungkan kemampuan argumentasi ilmiah dalam memahami konsep fisika secara utuh. Siswa mampu mengetahui tingkat pemahamannya sendiri dalam memahami suatu konsep. Membangun pemahaman siswa dapat dilakukan dengan pembelajaran yang mengajak siswa memahami konsep melalui hubungan konsep dengan dunia nyata dan masalah yang secara langsung dapat siswa selesaikan. Menurut (Bern \& Erickson, 2001), pembelajaran kontekstual membantu siswa menghubungkan konten yang dipelajari pada kehidupan nyata". Secara tidak langsung, pembelajaran kontekstual mengarahkan siswa belajar materi dengan mengetahui penerapan dalam kehidupan sehari-hari. Kebermaknaan ini mengantarkan siswa mampu memahami konsep secara utuh. Proses pembelajaran berlangsung dalam bentuk aktivitas siswa dan pengalaman kerja, bukan transfer pengetahuan dari guru ke siswa. Strategi belajar lebih penting daripada hasilnya. Sebagai strategi pembelajaran lainnya, pembelajaran kontekstual dikembangkan dengan tujuannya agar lebih produktif dan bermakna. Pendekatan kontekstual dapat dijalankan tanpa harus mengubah kurikulum dan tatanan yang ada (Ekowati, 2015). 
Kemampuan siswa dalam memahami suatu konsep membutuhkan banyak penjelasan untuk mengonstruk pemahaman secara utuh. Dibutuhkan juga bantuan dalam menjelaskan banyak pemahaman dalam konsep fisika. Representasi adalah sesuatu yang melambangkan atau singkatan dari objek dan atau proses. Contoh di Fisika meliputi kata-kata, gambar, diagram, grafik, simulasi komputer, dan persamaan matematis. Beberapa representasi lebih konkret (misalnya, sketsa dan gerak dan diagram tubuh bebas) dan berfungsi sebagai referensi untuk konsep yang lebih abstrak seperti percepatan dan hukum kedua newton. Banyak representasi dapat membantu pemahaman siswa dalam merepresentasikan matematika yang dibutuhkan untuk memecahkan masalah secara kuantitatif. Kelebihan representasi dapat digunakan untuk membantu penerapan konsep dasar secara matematis. Misalnya, siswa dapat belajar menggunakan diagram tubuh bebas untuk membangun hukum kedua Newton dalam bentuk komponen-komponen sebagai petunjuk dalam pemecahan masalah. Akibatnya, banyak pendidik merekomendasikan penggunaan beberapa representasi untuk membantu siswa belajar dan memecahkan masalah (Bredekamp \& Rosegrant, 1992).

Periode terakhir ini penelitian mengenai kemampuan argumentasi ilmiah siswa pada bidang fisika terutama pendidikan fisika mengalami kemajuan. Banyak para ahli yang melakukan penelitian untuk mengetahui kemampuan argumentasi ilmiah siswa dalam memahami konsep fisika yang dilakukan dalam pembelajaran. Pentingnya penelitian mengenai kemampuan argumentasi ilmiah dikarenakan kemampuan argumentasi ilmiah mengarahkan siswa untuk berpikir kritis, analitis dan mampu memecahkan masalah. Penelitian mengenai kemampuan argumentasi ilmiah siswa dilakukan oleh (Eskin \& Ogan-Bekiroglu, 2013; Sampson \& Clark, 2008; Sampson, Grooms, \& Walker, 2011). Oleh karena itu, diperlukan penelitian tentang kemampuan argumentasi ilmiah siswa melalui pembelajaran kontekstual-multirepresentasi. Kenyataannya, penelitian yang selama ini dilaksanakan hanya sebatas mengungkapkan tentang kemampuan argumentasi ilmiah siswa yang rendah. Namun penelitian di bidang kemampuan argumentasi ilmiah melalui model pembelajaran kontekstual-multirepresentasi masih jarang ditemukan. Pada penelitian ini kemampuan argumentasi ilmiah siswa dikembangkan melalui pembelajaran kontekstual-multirepresentasi yang mengajak siswa mempelajari konsep fisika dengan menggabungkan konsep dan dunia nyata. Pengembangan kemampuan argumentasi ilmiah pada penelitian ini ditujukan untuk mengajak siswa berpikir lebih dalam tentang suatu permasalahan yang harus diselesaikan dengan konsep fisika.

\section{METODE}

Penelitian ini menggunakan mixed methods untuk mengeksplorasi secara lengkap subjek penelitian. Pendekatan mixed methods ini dapat memberikan pemahaman yang lebih baik terhadap masalah penelitian. Penelitian yang dilakukan menggunakan desain embedded experimental model dari (Ivankova, Creswell, \& Plano Clark, 2007) disajikan pada gambar 1.

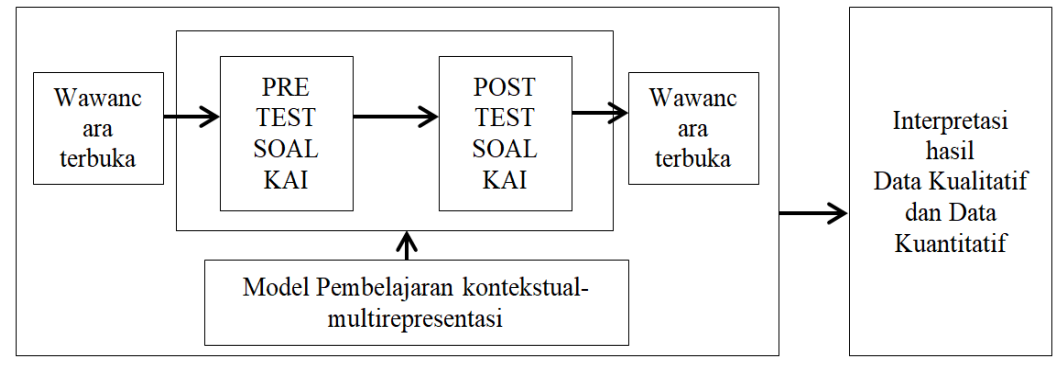

\section{Gambar 1. Metode Penelitian}

Metode penelitian yang ditentukan oleh peneliti dipilih melalui pertimbangan dan diskusi dengan ahli. Mixed Methods mampu membantu peneliti dalam memaparkan hasil penelitian secara kualitatif dan kuantitatif. Penelitian dilakukan di MAN 1 Kota Batu. Subjek penelitian ini adalah siswa kelas X tahun ajaran 2018-2019 yang ditentukan dengan cara purposive sampling yaitu siswa kelas X-MIA 1, X-MIA 2 pada materi gaya dan gerak. Analisis data menggunakan Uji beda Wilcoxon Test untuk mengetahui pengaruh model pembelajaran kontekstual berbasis multirepresentasi terhadap kemampuan argumentasi ilmiah siswa. Instrumen penelitian yang digunakan dalam penelitian ini terdiri atas instrumen pembelajaran dan instrumen pengukuran. Instrumen pembelajaran terdiri dari (a) Silabus, (b) RPP dan (c) LKS. Instrumen pengukuran terdiri dari (a) lembar observasi, (b) pedoman wawancara, (c) instrumen soal argumentasi ilmiah. Tes kemampuan argumentasi ilmiah berbentuk soal open ended bertingkat. Tes dilaksanakan sebelum pembelajaran (pretest) dan setelah pembelajaran (postest).

Hasil tes digunakan untuk mengukur kemampuan berargumentasi ilmiah siswa dan mendeskripsikannya. Hasil tes dikelompokkan pada masing-masing level yang digunakan sebagai pedoman penskoran kemampuan argumentasi ilmiah siswa. Penskoran dilakukan untuk mempermudah analisis kemampuan argumemtasi siswa pada masing-masing level. Analisis yang dilakukan adalah analisis kualitatif dan kuantitatif. Hipotesis dalam penelitian ini adalah sebagai berikut. 


\section{HASIL}

Data kriteria pencapaian kemampuan argumentasi ilmiah dianalisis berdasarkan jawaban dan disesuaikan dengan pedoman penskoran argumentasi. Penskoran argumentasi didasarkan pada kriteria Pola Argumentasi Toulmin yang dikembangkan oleh (Erduran, Simon, \& Osborne, 2004) berbentuk level yaitu level 1, level 2, level 3, level 4 dan level 5. Kriteria penskoran dimodifikasi agar mempermudah dalam pemilahan kriteria argumentasi ilmiah. Level 1 menyatakan argumentasi ilmiah terdiri dari claim, level 2 menyatakan argumentasi ilmiah terdiri dari claim yang disertai data. Level 3 menyatakan argumentasi ilmiah terdiri dari claim disertai data dan warrant. Level 4 menyatakan argumentasi ilmiah terdiri dari claim disertai data, warrant dan backing. Level 5 menyatakan argumentasi ilmiah terdiri dari claim disertai data, warrant dan backing dikuatkan dengan rebuttal. Pengelompokan kriteria argumentasi ilmiah dari pretest dan posttest dapat dilihat pada gambar 2.

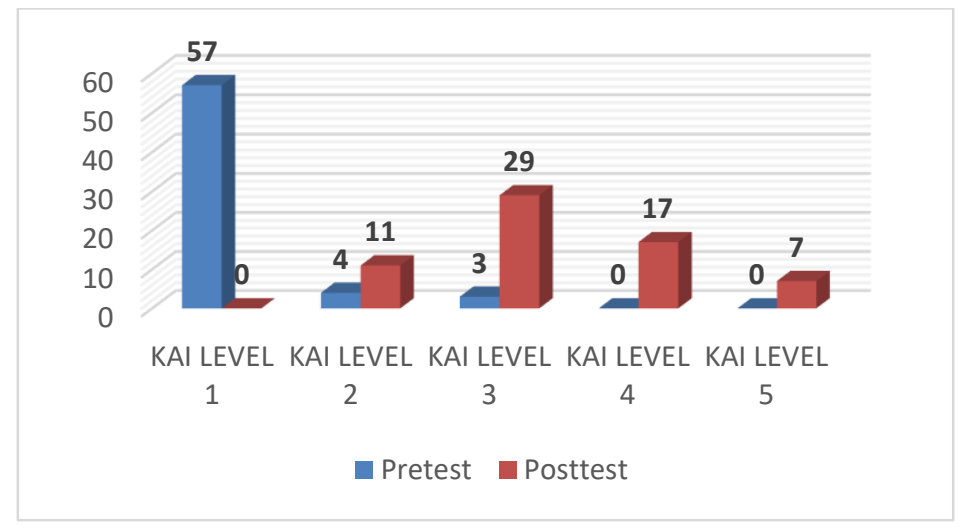

\section{Gambar 2. Pengelompokan Kriteria Argumentasi Siswa}

Gambar 2 tampak bahwa sebelum diterapkannya pembelajaran kontekstual, $89.06 \%$ siswa di level 1, 6.26\% siswa di level 2, 4.68\% siswa di level 3 dan 0\% siswa di level 4 dan 5. Data menunjukkan bahwa tingkat kemampuan argumentasi ilmiah siswa masih rendah yang dibuktikan dengan banyaknya siswa berada pada level 1. Argumentasi yang baik perlu didasari dengan pengetahuan konseptual yang cukup (Chen, Hand, \& McDowell, 2013). Kemampuan argumentasi ilmiah harus didukung dengan pengetahuan konseptual. Pengetahuan konseptual siswa mampu dibangun dengan pembelajaran yang bermakna yang mampu membangun konsep siswa terutama konsep fisika pada gaya dan gerak.

Kemampuan argumentasi ilmiah siswa dianalisis melalui jawaban siswa mengerjakan soal saat pretest dan postest. Untuk memberikan penjelasan ini diambil contoh soal nomor 1, 3, dan 6 yang kemampuan argumentasi ilmiah pada level rendah. Hasil analisis jawaban siswa saat pretest, pada soal nomor 1 dengan indikator soal menganalisis gerak benda pada lintasan lengkung dipaparkan pada gambar 3 .

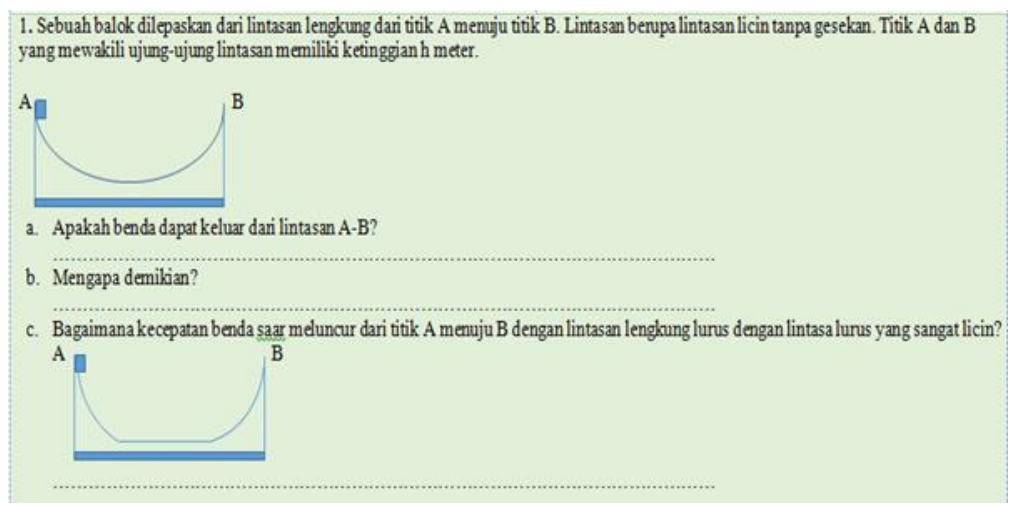

Gambar 3. Pemaparan Soal Kai No. 1 
Siswa diarahkan untuk menganalisis ketinggian yang mampu dicapai oleh pemain skateboard saat jatuh dari ketinggian tertentu. Banyak siswa menjawab bahwa pemain skateboard keluar dari lintasan yang sudah ditentukan. Dengan argumentasi yang diutarakan siswa bahwa kecepatan pemain skateboard saat jatuh sangat cepat dan membuat keluar dari lintasan, sedangkan soal nomor 3 ditunjukkan pada gambar 4.

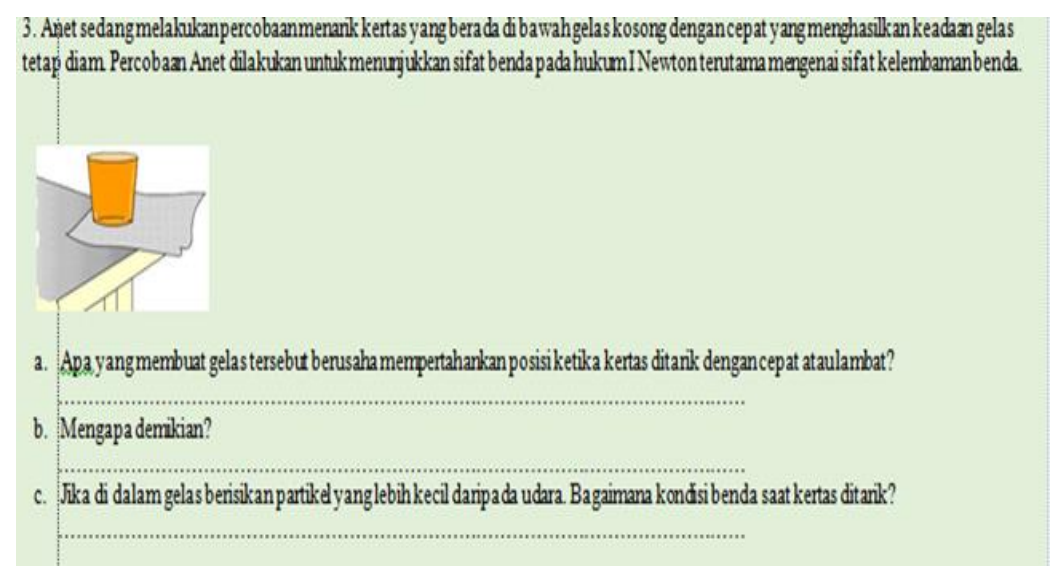

Gambar 4. Pemaparan Soal KAI No. 3

Pada soal nomor 5 dengan indikator soal menganalisis keadaan gelas kosong dan terisi air saat diletakkan di atas kertas, lalu kertas ditarik dengan cepat dan pelan. Hasilnya adalah banyak siswa menjawab, gelas kosong ketika ditarik cepat maka mengikuti arah tarikan, namun gelas yang berisi air akan tetap diam. Argumentasi yang diutarakan siswa menyatakan bahwa massa memengaruhi kondisi benda tanpa memperhatikan kerangka acuan benda. Sedangkan soal nomor 6 ditunjukkan pada gambar 5 .

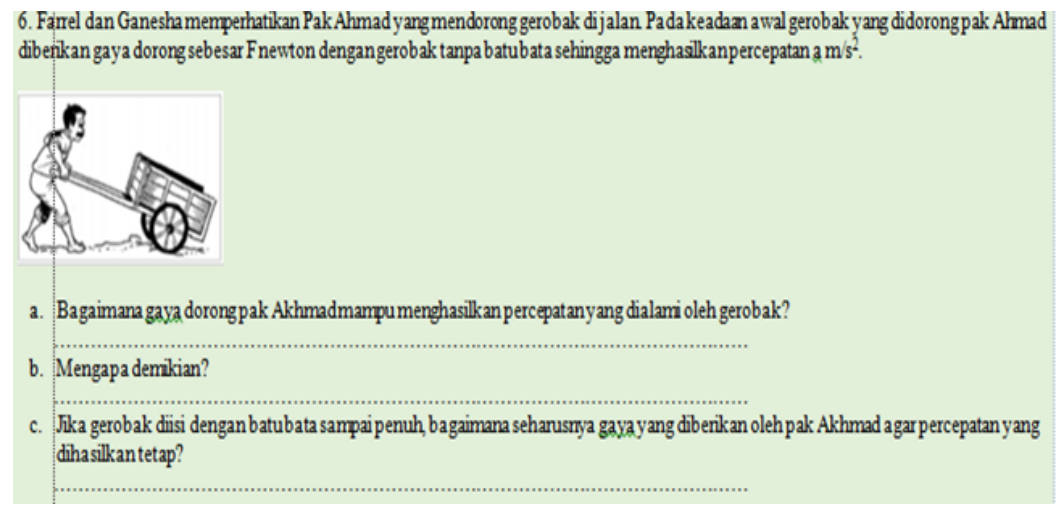

\section{Gambar 5. Pemaparan Soal KAI No. 6}

Pada soal nomor 6 dengan indikator soal menganalisis hubungan gaya, massa dan percepatan benda. Hasilnya adalah banyak siswa menjawab bahwa gaya, massa dan percepatan semuanya berbanding lurus. Argumen yang diutarakan oleh siswa menyatakan karena $\sum \vec{F}=m \vec{a}$ yang ditulis dalam segaris. Hasil wawancara menunjukkan juga kesulitan siswa dalam menjawab soal adalah dikarenakan kekurangan siswa dalam memahami materi. Kekurangan menjelaskan materi secara gamblang membuat siswa kesulitan dalam memahami materi. Jadi, ketika siswa kesulitan dalam memahami materi maka siswa juga kesulitan mengungkapkan argumentasi ilmiah. Penerapan model pembelajaran kontekstual-multirepresentasi mengajak siswa mempelajari fenomena dalam kehidupan sehari-hari dan membawa ke dalam kelas untuk dianalisis dengan konsep-konsep fisika. Siswa belajar melalui pengalaman pribadi dan mengonstruk pada teori fisika. Pembelajaran kontekstual mampu memengaruhi kemampuan argumentasi ilmiah siswa yang dibuktikan dari adanya peningkatan level yang dimiliki siswa. Setelah diterapkan model banyak bantuan yaitu diagram, gambar, fenomena alam, tabel atau video. Pembelajaran ini mengajarkan siswa belajar fisika pembelajaran kontekstual banyak siswa minimal berada pada level 2 yaitu sebanyak 17.18\%, pada level 3 sebanyak $43.75 \%$, pada level 4 sebanyak $37.13 \%$ dan pada level 5 sebanyak $10.94 \%$. 
Secara keseluruhan dapat dilihat adanya peningkatan dari pretest ke postest setelah diterapkan model pembelajaran kontekstual. Model pembelajaran kontekstual-multirepresentasi mengarahkan siswa mempelajari konsep fisika dengan secara langsung, sehingga konsep yang dimiliki siswa lebih bermakna. Kemampuan konseptual siswa yang baik mampu mengarahkan siswa membuat argumentasi dengan baik. Meningkatnya kemampuan argumentasi ilmiah siswa secara statistik dapat dilihat dapat tabel 1 dan 2.

Tabel 1. Hasil Analisis Wilcoxon Test pada Kemampuan Argumentasi Ilmiah

\begin{tabular}{lcccc}
\hline \multicolumn{5}{c}{ Ranks } \\
\hline & $\mathbf{N}$ & Mean Rank & Sum of Ranks \\
\hline \multirow{4}{*}{ Posttest-pretest } & Negative Ranks & $0^{\mathrm{a}}$ & .00 & .00 \\
& Positive Ranks & $64^{\mathrm{b}}$ & 32.50 & 2080.00 \\
& Ties & $0^{\mathrm{c}}$ & & \\
& Total & 64 & & \\
\hline
\end{tabular}

Tabel 2. Signifikansi Model Pembelajaran terhadap Kemampuan Argumentasi Ilmiah Siswa

\begin{tabular}{ll}
\hline \multicolumn{1}{c}{ J. } & K. Posttest - Pretest \\
\hline L. Z & N. $-7.140^{\mathrm{b}}$ \\
M. Asymp. Sig. (2-tailed) & O. .000 \\
\hline
\end{tabular}

Analisis data menggunakan Wilcoxon test menunjukkan nilai $\mathrm{Z}=-7.140$ dan value (Asymp. Sig 2 tailed) sebesar 0.000 di mana kurang dari batas kritis penelitian 0.05 sehingga keputusan hipotesis adalah menerima $\mathrm{H}_{1}$ yaitu terdapat pengaruh model pembelajaran terhadap kemampuan argumentasi ilmiah siswa. Hasil postest juga menunjukkan perubahan pola argumentasi yang diberikan oleh siswa. Jawaban siswa mengacu pada pengalam pribadi yang disesuaikan dengan konsep fisika. Pada soal nomor 1 siswa menjawab bahwa pemain skateboard tidak akan keluar dari lintasan dikarenakan sifat gerak benda itu sendiri. Dengan argumentasi "Jika benda diberikan gaya dari luar yang cenderung membuat benda bergerak maka benda akan bergerak dengan konstan dan jika benda melintasi lintasan lengkung maka ketinggian yang mampu dicapai benda adalah sama dengan ketinggian awal saat benda jatuh. Namun, jika benda dijatuhkan di luar lintasan maka benda akan keluar dari lintasan juga". Pada soal nomor 2, siswa menjawab bahwa kerangka acuan benda sangat diperlukan sehingga sebelum menentukan benda diam dan bergerak harus diketahui kerangka acuannya. Dengan argumentasi "Kerangka acuan sangat diperlukan dalam menentukan benda diam dan bergerak. Pada fenomena gelas, kerangka acuannya adalah gelas. Ketika gelas ditarik cepat maka gelas tetap diam dan tidak berubah posisi menyatakan bahwa gelas memenuhi Hukum I Newton yaitu sifat kelembaman. Namun, jika ditarik dengan pelan dan benda bergerak mengikuti tarikan maka gelas memiliki percepatan, dalam hal ini gelas memenuhi Hukum II Newton. Hubungan data kualitatif dan kuantitatif kemampuan argumentasi ilmiah siswa dijelaskan pada tabel 3, yaitu Crosstabulation kemampuan argumentasi ilmiah siswa dari pretest dengan posttest.

Tabel 3. Crosstabulation Kemampuan Argumentasi Ilmiah Siswa dari Pretest Dengan Posttest

\begin{tabular}{|c|c|c|c|c|c|c|}
\hline \multicolumn{7}{|c|}{ Posttest (\%) } \\
\hline & & 1 & 2 & 3 & 4 & 5 \\
\hline \multirow{5}{*}{ 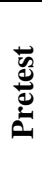 } & 1 & 0 & 0 & 18.75 & 53.125 & 15.625 \\
\hline & 2 & 0 & 0 & 1.5625 & 1.5625 & 4.6875 \\
\hline & 3 & 0 & 0 & 0 & 1.5625 & 3.125 \\
\hline & 4 & 0 & 0 & 0 & 0 & 0 \\
\hline & 5 & 0 & 0 & 0 & 0 & 0 \\
\hline
\end{tabular}

Hasil analisis menggunakan crosstabuation menunjukkan adanya peningkatan kemampuan argumentasi ilmiah siswa. Sebanyak $18.75 \%$ siswa pada level 1 mengalami peningkatan pada level 3, 53.125\% siswa mengalami peningkatan pada level 4 dan $15.625 \%$ mengalami peningkatan pada level 5. Pada level 2 menunjukkan bahwa $1.5625 \%$ siswa pada level 2 mengalami peningkatan pada level 3, 1.5625\% siswa pada level 2 mengalami peningkatan pada level 3, dan $4.6875 \%$ siswa pada level 2 mengalami peningkatan pada level 3. Pada level 3 menunjukkan bahwa $1.5625 \%$ siswa pada level 3 mengalami peningkatan pada level 4 dan 3.125\% siswa pada level 3 mengalami peningkatan pada level 5. Secara keseluruhan menunjukkan bahwa adanya peningkatan kemampuan argumentasi ilmiah siswa dengan meningkatnya level kemampuan argumentasi ilmiah. Pentingnya suatu pembelajaran dalam mengembangkan kemampuan siswa adalah dengan menerapkan pembelajaran bermakna yang mengajak siswa berperan langsung dalam pembelajaran. Sesuai penelitian (Kuhn, 2010) yang menyatakan argumentasi seseorang tidak 
hanya berbentuk secara teori, namun harus dibuktikan kebenarannya sehingga siswa tidak hanya mampu mengungkapkan apa saja teori yang diketahuinya, namun siswa harus mampu membuktikan kebenarannya. Penelitian lain yaitu Matuk (2015) menyatakan bahwa kemampuan argumentasi ilmiah dapat dibentuk karena pada kegiatan pembelajaran melibatkan gambar dan video, melakukan penemuan atau adanya data relevan yang disediakan.

\section{SIMPULAN}

Berdasarkan hasil analisis data dan pembahasan dapat disimpulkan bahwa persentase tingkat kemampuan berargumentasi ilmiah pada materi gaya dan gerak mengalami peningkatan. Dari hasil pretest kemampuan argumentasi ilmiah siswa banyak berada pada level 1, namun setelah postest hasil kemampuan argumentasi ilmiah siswa mengalami kenaikan yaitu tersebar pada level 2,3,4 dan 5. Pola kemampuan argumentasi ilmiah siswa ketika pretest, 57 siswa berada pada kategori kemampuan argumentasi ilmiah level 1, empat siswa berada pada kategori kemampuan argumentasi ilmiah level 2, dan tiga siswa berada pada kategori kemampuan argumentasi ilmiah level 3. Perubahan pola kemampuan argumentasi ilmiah siswa dari pretest ke posttest yaitu dari 57 siswa yang berada di level 1 mengalami perubahan level terdiri dari delapan siswa di level 2, 29 siswa di level 3, 16 siswa di level, dan lima siswa di level 5. Empat siswa yang berada di level 2 mengalami perubahan pola kemampuan argumentasi yaitu tiga siswa tetap di level 2 dan satu siswa di level 4, sedangkan tiga siswa yang berada di level 3 juga mengalami perubahan pola kemampuan argumentasi yaitu satu siswa berada di level 4 dan dua siswa berada di level 5. Model pembelajaran kontekstual-multirepresentasi mampu meningkatkan penguasaan konseptual siswa yang berakibat pada kemampuan argumentasi ilmiah siswa semakin baik.

Berdasarkan hasil analisis data kemampuan argumentasi ilmiah dan pembahasan, saran bagi sekolah sebaiknya sekolah mempertimbangkan kembali metode pembelajaran yang dapat digunakan untuk meningkatkan kemampuan berargumentasi siswa pada konsep gaya dan gerak. Bagi guru, sebaiknya sebelum pembelajaran diadakan tes lisan mengenai kemampuan berargumentasi ilmiah siswa agar guru mengetahui kelemahan siswa dalam menguasai konsep fisika.

\section{DAFTAR RUJUKAN}

Alias, S. N., \& Ibrahim, F. (2016). A Preliminary Study of Students' Problems on Newton's Law. International Journal of Business and Social Science, 7(4), 133-139.

Bern, R., \& Erickson, P. (2001). Contextual Teaching and Learning: Preparing Students for the New Economy, no. 5.

Bredekamp, S., \& Rosegrant, T. (1992). Guidelines for Appropriate Curriculum Content and Assessment. National Association for The Education of Young Children, 1(2), 9-27.

Chen, Y. C., Hand, B., \& McDowell, L. E. A. H. (2013). The Effects of Writing-to Learn Activities on Elementary Students' Conceptual Understanding: Learning about Force and Motion Through Writing to Older Peers. Science Education, 97(5), 745-771.

Ekowati, C. (2015). The Application of Contextual Approach in Learning Mathematics to Improve Students Motivation at SMPN 1 Kupang. International Education Studies, 8(8), 81-86.

Erduran, S., Simon, S., \& Osborne, J. (2004). Tapping into Argumentation: Developments in the Application of Toulmin's Argument Pattern for Studying Science Discourse. Science Education, 88(6), 915-933.

Eskin, H., \& Ogan-Bekiroglu, F. (2013). Argumentation as a Strategy for Conceptual Learning of Dynamics. Research in Science Education, 43(5), 1939-1956. https://doi.org/DOI : 10.1007/s11165-01209339-5

Halim, L., Yong, T. K., \& Meerah, T. S. M. (2014). Overcoming Students' Misconceptions on Forces in Equilibrium: An Action Research Study. Creative Education, 5(11), 1032.

Ivankova, N. V, Creswell, J. W., \& Plano Clark, V. L. (2007). Foundations and Approaches to Mixed Methods Research. First Steps In Research. Pretoria: Van Schaik, 253-282.

Kuhn, D. (2010). Teaching and Learning Science as Argument. Science Education, 94(5), 810-824.

National Research Council. (2008). Desalination: A National Perspective. Washington, DC: The National Academies Press.

Osborne, J. (2010). Arguing to Learn in Science: The Role of Collaborative, Critical Discourse. Science, 328(5977), 463-466.

Sampson, V., \& Clark, D. B. (2008). Assessment of The Ways Students Generate Arguments in Science Education: Current Perspectives and Recommendations for Future Directions. Science Education, 92(3), 447-472.

Sampson, V., Grooms, J., \& Walker, J. P. (2011). Argument-Driven Inquiry as a way to Help Students Learn How to Participate in Scientific Argumentation and Craft Written Arguments: An Exploratory Study. Science Education, 95(2), $217-257$.

Wang, J., \& Buck, G. A. (2016). Understanding a High School Physics Teacher's Pedagogical Content Knowledge of Argumentation. Journal of Science Teacher Education, 27(5), 577-604. 